\title{
USING BEES ALGORITHMS FOR SOLUTION OF RADAR PAVEMENT MONITORING INVERSE PROBLEM
}

\author{
Alexander Krainyukov, Valery Kutev, Elena Andreeva
}

\author{
Transport and Telecommunications Institute \\ Lomonosova iela 1, Riga, LV-1019, Latvia \\ Ph.:+(371) 67100634. Fax: +(371) 67100660 \\ E-mail: Krainukovs.A@tsi.lv,Kutevs.V@tsi.lv,jelenka.andrejeva@gmail.com
}

\begin{abstract}
This work has focused on using of Bee Algorithm and Artificial Bee Colony algorithm for solution the inverse problem of subsurface radar probing in frequency domain. Bees Algorithms are used to minimize the aim function. Tree models of road constructions and their characteristics have been used for solution of the subsurface radar probing inverse problem. There has been investigated the convergence of $\mathrm{BA}$ and $\mathrm{ABC}$ algorithms at minimisation of the aim function of the inverse problem of radar subsurface probing of roadway structures. There has been investigated the impact of free arguments of BA and ABC algorithm, width of the frequency range and width of the searching interval on the error of reconstruction of electro-physical characteristics of layers and duration of algorithm operating. There has been investigated the impact of electro-physical characteristics of roadway structure layers and width of the frequency range on aim function of radar pavement monitoring inverse problem.
\end{abstract} algorithm

Keywords: radar monitoring, inverse problem, electro-physical parameters, Bee Algorithm, Artificial Bee Colony

\section{Introduction}

Monitoring and evaluation of pavement condition is important in roadway pavement engineering and management. The in-service performance of the roadway pavement depends on consistent, costeffective and accurate monitoring of condition for early scheduling of repair and maintenance [1-4]. Modern ground - penetrating radar (GPR) are widely used for monitoring of roadway pavement [1, 3-6]. GPR provide radar profiles of pavement. Radar profiles give only a qualitative picture of the pavement structure and its state usually. It is necessary to perform reconstruction of the pavement electro-physical characteristics with detection and identification of inner zones and objects of pavement. Reconstruction of electro-physical characteristics of the pavement structural elements is in essence identification of electrophysical characteristics of the pavement layers, which can be achieved by solving the inverse problem of radar pavement probing.

In [7] the radar pavement inverse problem has been investigated in the frequency domain. The solution of the inverse problem of radar probing had been received in the frequency domain by method of selection. The aim function $\Phi$ is used in the following form:

$\Phi=\frac{1}{n_{\max }} \sum_{i=0}^{n_{\max }}\left|\dot{S}_{e}\left(\omega_{i}, \vec{P}\right)-\dot{S}_{t}\left(\omega_{i}, \vec{P}_{M}\right)\right|^{2}$,

where $\mathrm{n}_{\max }$ is a number of the spectral component with frequency $\mathrm{f}_{\max } ; \mid \dot{S}_{e}\left(\omega_{i}, \vec{P}\right)$ is the complex spectral density from the reflected signal and is function of parameter vector $\vec{P}$ for angular frequency $\omega_{i}$; $\left|\dot{S}_{t}\left(\omega_{i}, \vec{P}_{M}\right)\right|$ is the complex spectral density, which is derived from the solving of forward problem of GPR probing. $\left|\dot{S}_{t}\left(\omega_{i}, \vec{P}_{M}\right)\right|$ is function of parameter vector $\vec{P}_{M}$ for angular frequency $\omega_{i}$. The vector $\vec{P}=\left\{p_{1}, p_{2}, \ldots, p_{n}\right\}$, in which components $p_{i}$ are electro-physical parameters of layers for n-layered probed roadway pavement. Electro-physical parameters of each layer are: thickness $h$, conductivity $\sigma$ and the relative dielectric permittivity $\varepsilon^{\prime}$ of the layer's materials. The solution of the inverse problem was the vector of parameters $\vec{P}_{M}$, which corresponds to the global minimum of the aim function $\Phi$. 
To calculate $B_{t}\left(\omega_{i}, \vec{P}_{M}\right)$ the vector of parameters $\vec{P}_{M}$ was limited by the set of allowed values of parameters $\vec{P}_{P O S}$. An iterative procedure was used to select of electro-physical characteristics values and to find of the aim function $\Phi$ global minimum. Results and the duration of the inverse problem solution depends on the algorithm that is used to search the global minimum $\Phi[5,7]$.

Bee Algorithm (BA) [8] and Artificial Bee Colony (ABC) algorithms [9] are the latest multi-agent behavioural methods of global optimisation that are used to solve various practical problems of search and optimisation. In [10] algorithms have been described to solve the inverse problem of the radar pavement monitoring with employment of $\mathrm{BA}$ and $\mathrm{ABC}$ algorithms.

In this work $\mathrm{BA}$ and $\mathrm{ABC}$ algorithms have been used to solve the inverse problem of the radar pavement monitoring father. We research the effect of $\mathrm{BA}$ and $\mathrm{ABC}$ characteristics on the results of inverse problem solution. The peculiarities of aim functions (1), which correspond to the tree electrophysical models of the road structures, are researched too.

\section{Forward Modelling of Subsurface Pavement Radar Probing}

Generally, any road structure consists of a road surfacing, road foundation and subgrade (subsoil). The roadway surfacing and the road foundation form road pavement of any roadway structure. All pavements are usually subdivided into flexible and rigid on the bending resistance [10].

The flexible pavements: the pavements with layers arranged from different kinds of asphalt concrete (tarmacadam), of materials and soils, stabilized with bitumen, cement, lime and other complex cohesive substances, as well as of weakly granular materials (crushed stone, slag, gravel, etc. ). On Figure 1 a generalized the roadway structure with flexible pavement is shown, which consists of three aforenamed points [1].

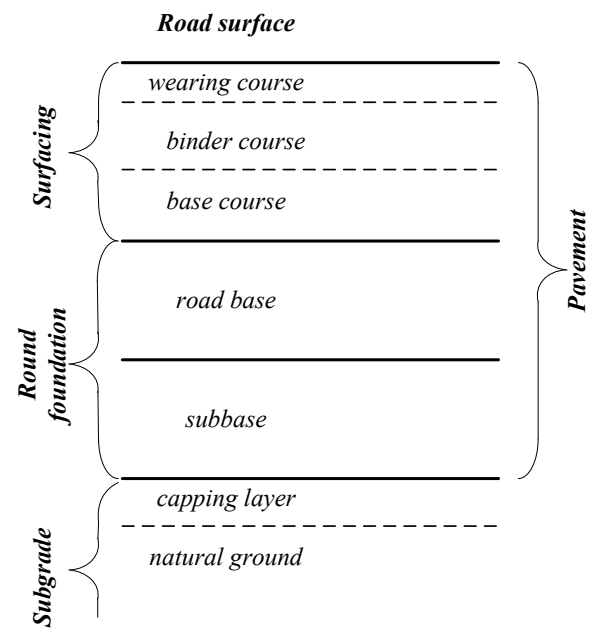

Figure 1. Roadway structure with flexible pavement

Analysis of the types of road constructions shows that their structural elements having the same functionality, either performed from the same material or of materials having similar values of the electro-physical characteristics. The main differences are in the number and thickness of the structural layers of road constructions [10]. The road length, corresponding to SV / I / II / III classes loads, is more than $60 \%$ of the total road length in Latvia. Therefore three models were determined for road of SV / I / II / III classes loads. These models were used in the work in investigations of reconstruction electrical parameters of roadway constructions.

The electro-physical parameters of the modelled of the roadway constructions are presented in Tables 1-3. The electro-physical parameters of the roadway constructions has been modelled taking into account that the roadway layers are composed of such materials as asphalt, concrete, crushed stone, crushed slag, sand and others. The number of the layers can vary but the electro-physical characteristics of some layers can be very similar or even equal. Electro-physical parameters of the model partial layers as well as the parameters of two semi-infinite spaces: upper space - air, and low space - subgrade. 
Table 1. Electro-physical parameters of the road structure layers (model 1)

\begin{tabular}{|c|c|c|c|c|}
\hline \multirow{2}{*}{$\begin{array}{c}\text { Number } \\
\text { of } \\
\text { layer }\end{array}$} & Layer material & \multicolumn{2}{|c|}{ Electro-physical parameters of layer material } \\
\cline { 2 - 4 } & & $\mathcal{E}^{\prime}$ & $\sigma, \mathrm{s} / \mathrm{m}$ & $\mathrm{h}, \mathrm{m}$ \\
\hline 1 & Air & 1 & 0 & $\infty$ \\
\hline 2 & Dense grated HMA & 2,9 & 0 & 0,06 \\
\hline 3 & Coarse-grained asphalt 2 marks & 3,6 & 0 & 0,08 \\
\hline 4 & Coarse asphalt 2 marks & 5,0 & $0^{-6}$ & 0,12 \\
\hline 5 & Crushed stone & 7,0 & $5^{*} 10^{-4}$ & 0,33 \\
\hline 6 & Sand & 9,0 & $5^{*} 10^{-3}$ & 0,65 \\
\hline 7 & Loam & 15,0 & $5^{*} 10^{-2}$ & $\propto$ \\
\hline
\end{tabular}

Table 2. Electro-physical parameters of the road structure layers (model 2)

\begin{tabular}{|c|c|c|c|c|}
\hline \multirow{2}{*}{$\begin{array}{c}\text { Number } \\
\text { of } \\
\text { layer }\end{array}$} & Layer material & \multicolumn{3}{|c|}{ Electro-physical parameters of layer material } \\
\cline { 3 - 5 } & & $\dot{\varepsilon}^{\prime}$ & $\sigma, \mathrm{s} / \mathrm{m}$ & $\mathrm{h}, \mathrm{m}$ \\
\hline 1 & Air & 1 & 0 & $\infty$ \\
\hline 2 & Asphalt-concrete & 4,5 & 0 & 0,15 \\
\hline 3 & Crushed stone & 7 & 0,0005 & 0,33 \\
\hline 4 & Sand & 9 & 0,005 & 0,65 \\
\hline 5 & Loam & 15 & 0,05 & $\propto$ \\
\hline
\end{tabular}

Table 3. Electro-physical parameters of the road structure layers (model 3)

\begin{tabular}{|c|c|c|c|c|}
\hline \multirow{2}{*}{$\begin{array}{c}\text { Number } \\
\text { of } \\
\text { layer }\end{array}$} & Layer material & \multicolumn{3}{|c|}{ Electro-physical parameters of layer material } \\
\cline { 3 - 5 } & & $\varepsilon^{\prime}$ & $\sigma, \mathrm{s} / \mathrm{m}$ & $\mathrm{h}, \mathrm{m}$ \\
\hline 1 & Air & 1 & 0 & $\infty$ \\
\hline 2 & Asphalt-concrete & 4,5 & 0 & 0,15 \\
\hline 3 & Crushed stone & 7 & 0,0005 & 0,40 \\
\hline 4 & Loam & 15 & 0,05 & $\propto$ \\
\hline
\end{tabular}

Forward problem of the flexible pavement structure GPR probing was solving numerically with the using of the frequency model of signal forming channel for subsurface GPR probing of flexible pavement described in [12]. Calculations were carried out under the following conditions: distance between the antennas $-1 \mathrm{~m}$; antennas high over upper boundary $-0.05 \mathrm{~m}$; half length of linear antennas $-0,25 \mathrm{~m}$; diameter of antennas $-0,0025 \mathrm{~m}$; load resistor of the receiving antenna $-425 \mathrm{Om}$.

The probing signal was generated by the shock excitation of the transmitting antenna by triangular video, pulse duration of which was equal to $2 \mathrm{~ns}$, and it was equal to $100 \mathrm{~V}$. Complex transfer function $\dot{K}_{R A D}(\omega, \vec{P})$ is calculated according to [12] for vector $\vec{P}$, components of which are corresponded data presented in Table 1-Table 3. The spectrum of receiving signal is computed in the following form:

$\dot{S}_{T}(\omega)=\dot{K}_{R A D}(\omega) \cdot \dot{S}_{e x}(\omega)$, where $\dot{S}_{e x}(\omega)=\int_{-\infty}^{\infty} u_{e x}(t) \cdot e^{-j \omega t} d t$

is spectrum of excitation signal $u_{e x}(t) . \dot{S}_{T}(\omega)$ was used in expression (1) to calculate the aim function $\Phi$. 


\section{Reconstruction of Electro-Physical Characteristics of Roadway Construction Model with Employment of BA and ABC Algorithms}

There is investigation of peculiarities of solving the inverse problem of ar subsurface probing of roadway construction model with employment of $\mathrm{BA}$ and $\mathrm{ABC}$ algorithms [10]. Solution of the inverse problem has been performed with implementation three electro-physical models of roadway construction (Tables 1-3).

The following fundamental values of free arguments of BA algorithm have been employed for searching for the global minimum of aim function $\Phi$ : number of bees-scouts - 25; number of selected (the fittest) sites -7 ; number of elite sites -3 ; number of bees-foragers sent to the elite sites -5 ; number of bees-foragers sent to the prospective sites -2 ; maximum number of iterations - 100; maximum number of iterations without improvement of the obtained value of aim function -4 ; size of sites for local searching $-5 \%$ of the width of searching interval for every electro-physical characteristic of roadway construction model. The following basic values of free arguments of BA algorithm have been selected for searching the global minimum of the aim function: number of bees-scouts -25 ; maximum number of iterations - 150; maximum number of iterations, not followed by improvement of the aim function value of every bee-scout -10 .

The procedure of investigating the possibilities of $\mathrm{BA}$ and $\mathrm{ABC}$ algorithms has comprised varying the conditions of solving the inverse structural problem of radar subsurface probing of the road constructions:

- maximum frequency of spectral density $\dot{S}_{e}(\omega)$ for calculating the aim function of inverse problem (1);

- search intervals for every electro-physical characteristic of modelled roadway construction.

The results of solving the inverse structural problem with employment of BA and ABC algorithms (the vector of the reconstructed parameters of modelled roadway construction $\vec{P}_{M}^{*}$ and found minimal values of the aim function) have been employed for assessment of such values as:

- relative error of reconstructing every characteristic of modelled construction; the error is determined as a relative mean square deviation of reconstructed parameter of modelled construction;

- mean number of iterations necessary for completing BA and ABC operations;

- probability of positioning every reconstructed electro-physical characteristic of roadway construction model;

- absolute error of finding the minimum of mean value of specified minimal values of aim function;

- convergence of BA and ABC algorithms.

Solution of the inverse problem with the specified values of free arguments BA and ABC algorithms and conditions of searching for the global minimum of the aim function has been implemented iteratively - 100 times - for excluding the impact of this factor on the research results. The obtained set of independent solutions has been employed for finding the statistical estimations of the values listed above.

Figure 2 demonstrates the results of minimization of aim function $\Phi$ for model 1 of roadway construction at different relative values of searching intervals with employment of BA (Fig. 2a) and ABC (Fig. 2b) algorithms. The algorithm operations has completed after accomplishing 150 iterations. Maximum frequency of spectrum for calculating the aim function $f_{\max }=500 \mathrm{MHz}$. These dependencies describe the convergence of $\mathrm{BA}$ and $\mathrm{ABC}$ algorithms.

The obtained mean values of minimal values of aim function significantly grow at expanding searching intervals. It is seen that the velocity of algorithm convergence gradually goes down with the growth of intervals width. Nevertheless, even at the minimal searching interval the error of finding the minimal value of aim function is far from zero. The BA algorithm allows finding smaller values of aim function at narrowing search range compared with the $\mathrm{ABC}$ algorithm.

Table 4 demonstrates the relative errors of reconstruction of the electro-physical characteristics (EPC) of model 1 of roadway structure after accomplishing the $150^{\text {th }}$ iteration of BA and ABC algorithms. Values of relative errors are provided in percent. In case of insufficient a priori information (the relative searching interval width is $50 \%$ ) the relative error of reconstructing the thickness of layers 
decreases approaching to 5\% excluding the reconstruction error for the fourth layer. In case of smaller relative searching intervals the relative error of reconstructing the thickness of layers does not exceed $3 \%$.

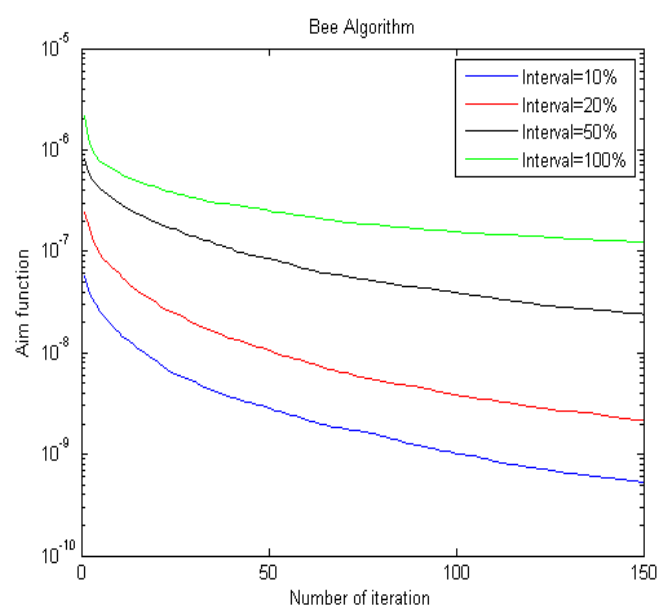

a

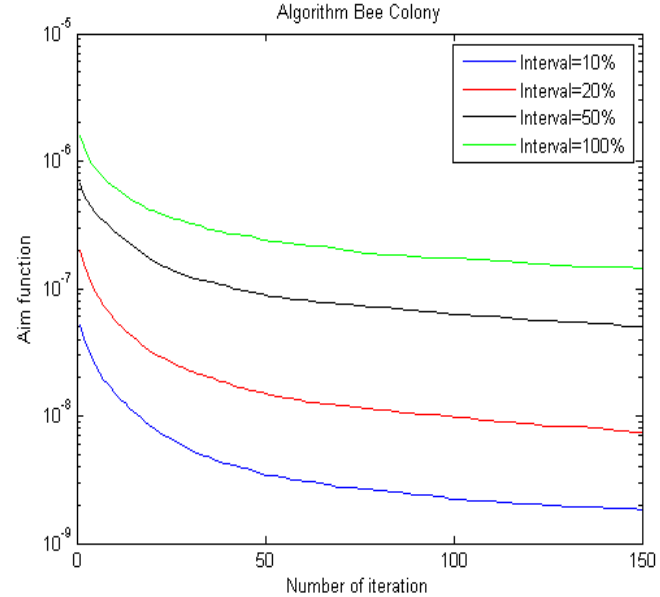

b

Figure 2. Influence of relative width of electro-physical characteristic search range on convergence of BA (a) and $\mathrm{ABC}(\mathrm{b})$ algorithms (model 1 of roadway construction)

Table 4. The relative errors of reconstruction of the electro-physical characteristics of model 1 of roadway construction

\begin{tabular}{|c|c|c|c|c|c|c|c|c|}
\hline \multirow[t]{2}{*}{ Electro-physical characteristics } & \multicolumn{4}{|c|}{$\begin{array}{l}\text { BA algorithm } \\
\text { The relative search interval width, } \%\end{array}$} & \multicolumn{4}{|c|}{$\begin{array}{l}\text { ABC algorithm } \\
\text { The relative search interval width, } \%\end{array}$} \\
\hline & 10 & 20 & 50 & 100 & 10 & 20 & 50 & 100 \\
\hline $\mathrm{h}_{1}$ & 0.8 & 1.1 & 4.2 & 8.3 & 1.0 & 2.1 & 5.0 & 9.2 \\
\hline $\mathrm{h}_{2}$ & 0.4 & 0.8 & 2.7 & 4.5 & 0.75 & 1.6 & 4.1 & 6.5 \\
\hline $\mathrm{h}_{3}$ & 0.8 & 1.1 & 4.9 & 11.0 & 1.1 & 1.8 & 4.0 & 6.6 \\
\hline $\mathrm{h}_{4}$ & 0.2 & 0.4 & 8.0 & 25.5 & 0.6 & 1.0 & 3.5 & 22.5 \\
\hline $\mathrm{h}_{5}$ & 0.7 & 0.9 & 5.7 & 26.2 & 0.55 & 1.4 & 3.6 & 18.5 \\
\hline$\varepsilon_{1}^{\prime}$ & 0.03 & 0.06 & 0.4 & 0.6 & 0.1 & 0.2 & 0.5 & 0.7 \\
\hline$\varepsilon_{2}^{\prime}$ & 0.2 & 0.6 & 2.4 & 4.5 & 0.6 & 1.2 & 3.33 & 6.5 \\
\hline$\varepsilon_{3}^{\prime}$ & 1.2 & 2.4 & 9.2 & 10.8 & 1.6 & 3.4 & 4.4 & 23.8 \\
\hline$\varepsilon_{4}^{\prime}$ & 2.1 & 3.5 & 12.1 & 29.0 & 1.5 & 4.1 & 11.3 & 33.5 \\
\hline$\varepsilon_{5}^{\prime}$ & 2.8 & 4.2 & 13.4 & 23.0 & 1.8 & 4.4 & 10.3 & 23.5 \\
\hline$\varepsilon_{6}^{\prime}$ & 3.3 & 5.5 & 14.9 & 27.4 & 2.7 & 5.0 & 13.5 & 27.2 \\
\hline$\sigma_{4}$ & 3.2 & 6.4 & 13.5 & 31.8 & 3.0 & 5.1 & 13.8 & 27.1 \\
\hline$\sigma_{5}$ & 3.2 & 6.3 & 15.1 & 31.8 & 2.5 & 5.0 & 13.4 & 26.8 \\
\hline$\sigma_{6}$ & 3.3 & 6.2 & 14.8 & 29.0 & 2.5 & 5.1 & 13.7 & 28.0 \\
\hline
\end{tabular}

If searching interval of $100 \%$ the value of relative errors of reconstructing the thickness of layers indicates that the reconstructed values of thickness are dispensed according to the uniform law in the searching interval. Only the thickness of the second layer can be reconstructed with error close to $5 \%$. 
If $\mathrm{ABC}$ algorithm is used in case the relative width of the searching interval of layer thickness does not exceed $50 \%$, the reconstruction of thickness of any layer can be completed with relative error of less than $5 \%$. In case of decreasing the relative width of searching interval the relative error of reconstruction of thickness of layer is less than $3 \%$. The ABC algorithm provides reconstruction of the layer thickness with a high accuracy of at least insufficient prior information.

The value of relative dielectric permittivity of the first layer is reconstructed with error less than $1 \%$, and the value of relative dielectric permittivity of the second layer with error less than $5 \%$ at any a priori information and does not depend on the algorithm. The relative errors of reconstructing the relative dielectric permittivity and the specific electrical conductivity of lower layers of roadway construction model practically do not depend on the algorithm, and their values are close to root mean square deviation of uniform law of random quantity, in other words the relative error is determined by specified searching interval.

Table 5 presents the results of the aim functions minimization for all models of roadway construction with algorithm BA: the mean and root mean square deviations of the obtained minimal values of aim functions after accomplishing the $150^{\text {th }}$ iteration of BA. These values for model 1 of roadway construction are also presented in Fig. 2.a. Analysis of mean minimal values of aim function reveals that decreasing number of characteristics of the aim function from 14 (model 1 of roadway construction, Table 1) to 10 (model 2, Table 2) and 7 (model 3, Table 3) does not improve the accuracy of aim functions minimization for inverse problem of radar subsurface probing of roadway constructions. The searching intervals width of electro-physical parameters of layers of roadway construction, in other words the degree of a priori information about the roadway construction, presents the principal influence on the aim functions minimisation.

Table 5. The results of the aim functions minimization for all models of roadway construction with BA algorithm

\begin{tabular}{|c|c|c|c|c|}
\hline \multirow{3}{*}{$\begin{array}{l}\text { Model of roadway } \\
\text { construction }\end{array}$} & \multicolumn{4}{|c|}{ The mean of aim function } \\
\hline & \multicolumn{4}{|c|}{ The relative search range width, \% } \\
\hline & 10 & 20 & 50 & 100 \\
\hline Model 1 & $5.0 * 10^{-10}$ & $2.1 * 10^{-9}$ & $2.4^{*} 10^{-8}$ & $1.2 * 10^{-7}$ \\
\hline Model 2 & $5.0 * 10^{-10}$ & $1.5^{*} 10^{-9}$ & $2.5^{*} 10^{-8}$ & $2.2 * 10^{-7}$ \\
\hline Model 3 & $1.8 * 10^{-10}$ & $7.8^{*} 10^{-10}$ & $4.3^{*} 10^{-9}$ & $2.0 * 10^{-8}$ \\
\hline
\end{tabular}

Table 6 demonstrates the relative errors of reconstruction of the electro-physical characteristics of models 2 and 3 of roadway construction with employment of aim function after accomplishing the $150^{\text {th }}$ iteration of BA.

The comparative analysis of values presented by Table 6 and values of relative errors of reconstruction of the electro-physical characteristics of model 1 of roadway construction (Table 4) shows:

1. Increased thickness of the first layer $h_{1}$ in models 2 and 3 of roadway construction results in the situation when the error of reconstructing this parameter significantly depends on a priori information (from relative width of searching interval). The errors of reconstruction of the thickness of lower layers of models 2 and 3 of roadway construction are substantially lower than the errors of reconstruction of the thickness of similar layers of model 1 and do not depend on a priori information. It is explained by high level of signals, reflected from the boundaries of lower layers of models 2 and 3 of roadway construction.

2. The relative dielectric permittivity of two upper layers of roadway construction of models 2 and 3 are reconstructed with rather high accuracy independently from the searching interval width similar to the relative dielectric permittivity of two upper layers of model 1 . The error of reconstructing the relative dielectric permittivity of lower layers of models 2 and 3 has the same values as at reconstructing the relative dielectric permittivity of lower layers of model 1 and depends on the searching interval width.

3. The error of reconstruction of the relative dielectric permittivity of layers of models 2 and 3 is only determined by the searching interval width of the corresponding parameter; the same happens for model 1 of roadway covering.

Values of the relative errors of reconstruction of the electro-physical characteristics of all models of roadway construction and the influence on them the search interval widths are explained by to the degree of influence of each the electro-physical characteristic on the aim function (1). Figures 3, 4 and 5 show 
the cross section of the aim function along all electro-physical characteristics (directions). The cross-sections of the aim function along the relative dielectric permittivity of the all layers of models are asymmetrical (Figure 3). Degree of asymmetry of the cross-sections is different. The cross-section along the relative dielectric permittivity of the second and third layers have the greatest asymmetry. The aim function increases more slowly, if the value of the relative dielectric permittivity of each layer increases with respect to the model value.

Table 6. The relative errors of reconstruction of the electro-physical characteristics of models 2 and 3 of roadway construction

\begin{tabular}{|c|c|c|c|c|c|c|c|c|}
\hline \multirow{3}{*}{ Electro-physical characteristics } & \multicolumn{4}{|c|}{ Model 2} & \multicolumn{4}{|c|}{ Model 3} \\
\hline & \multicolumn{4}{|c|}{ The relative search range width, $\%$} & \multicolumn{4}{|c|}{ The relative search range width, $\%$} \\
\hline & 10 & 20 & 50 & 100 & 10 & 20 & 50 & 100 \\
\hline $\mathrm{h}_{1}$ & 2.3 & 5.6 & 12.4 & 24.8 & 1.3 & 2.8 & 5.8 & 12.9 \\
\hline $\mathrm{h}_{2}$ & 0.4 & 1.8 & 3.4 & 4.4 & 0.2 & 0.5 & 1.1 & 2.5 \\
\hline $\mathrm{h}_{3}$ & 0.4 & 1.6 & 2.6 & 1.6 & - & - & - & - \\
\hline$\varepsilon_{1}^{\prime}$ & 0.4 & 1.1 & 2.2 & 4.2 & 0.2 & 0.5 & 1.1 & 2.4 \\
\hline$\varepsilon_{2}^{\prime}$ & 0.7 & 3.6 & 5.2 & 18.0 & 0.4 & 0.9 & 2.2 & 4.4 \\
\hline$\varepsilon_{3}^{\prime}$ & 1.4 & 5.7 & 10.6 & 26.8 & 1.9 & 4.4 & 10.6 & 22.5 \\
\hline$\varepsilon_{4}^{\prime}$ & 2.4 & 6.8 & 13.7 & 28.6 & - & - & - & - \\
\hline$\sigma_{2}$ & 2.9 & 6.7 & 14.0 & 30.2 & 2.9 & 5.6 & 15.1 & 31.2 \\
\hline$\sigma_{3}$ & 2.8 & 5.7 & 14.0 & 27.7 & 2.7 & 6.1 & 14.2 & 29.4 \\
\hline$\sigma_{4}$ & 2.6 & 5.5 & 14.0 & 25.4 & - & - & - & - \\
\hline
\end{tabular}

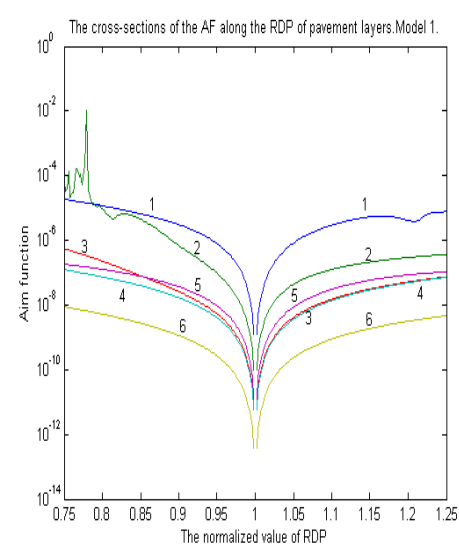

a

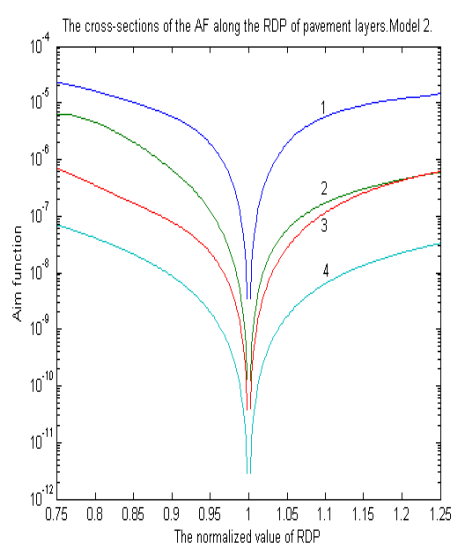

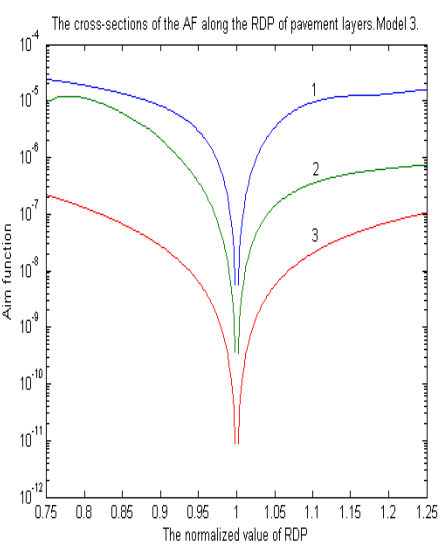

c

Figure 3. Model-based cross - sections of the aim function along relative dielectric permittivity of pavement layers: a - model 1; $\mathrm{b}-$ model $2 ; \mathrm{c}-$ model 3 (digit near the line is the number of layer)

The cross-sections of the aim function along the thickness of the all layers are symmetrical (Figure 4). The local maximums and local minimums are presented at the cross sections of the aim function along the thickness of the bottom layers of every model of roadway construction (the $5^{\text {th }}$ line on Fig. $4 \mathrm{a}$, the $3^{\text {rd }}$ line on Fig. $4 \mathrm{~b}$ and the $2^{\text {nd }}$ line on Fig. 4c). This can be explained by large thicknesses of these layers. The cross-sections of the aim function along the specific electrical conductivity of the all layers of models are perfectly symmetrical for all layers as it is shown on Figure 5. 
The maximum values of the aim function for each section characterize the sensitivity to changes in the aim function of each parameter. The aim function is most sensitive to changes in the relative dielectric permittivity of the first layers (the $1^{\text {st }}$ lines on Fig. 3a, 3b and 3c) of all three models. The aim function has high sensitivity to changes in the relative dielectric permittivity of the second layers and the thickness of the second layers (the $2^{\text {nd }}$ lines on Fig. $4 a, 4 b$ and $4 c$ ) of all three models, also to changes in the thickness of the lower layers (the $5^{\text {th }}$ line on Fig. $4 \mathrm{a}$, the $3^{\text {rd }}$ line on Fig. $4 \mathrm{~b}$ ) of the first and second models. The aim function has the lowest sensitivity to the changing in specific electrical conductivity of all layers of the tree models (Fig. 5) in comparison to the sensitivity to the changing in relative dielectric permittivity and thickness of layers.

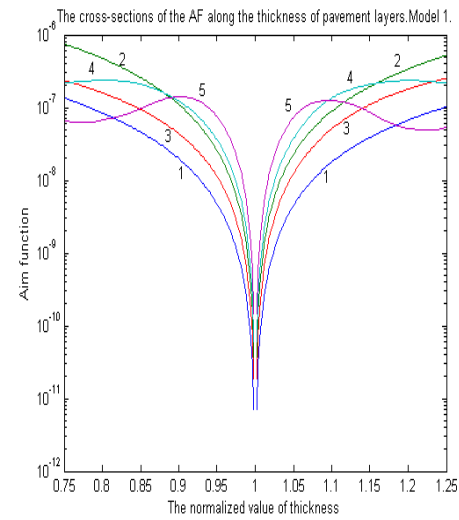

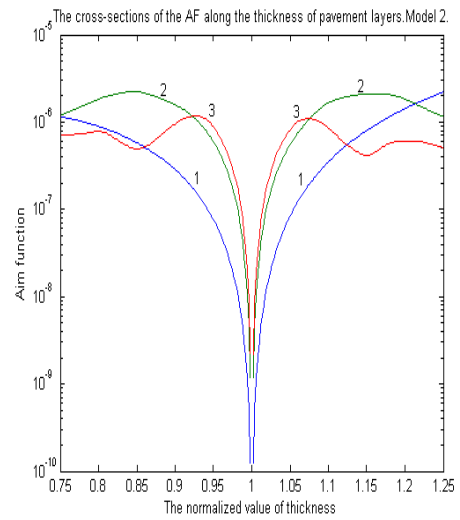

b

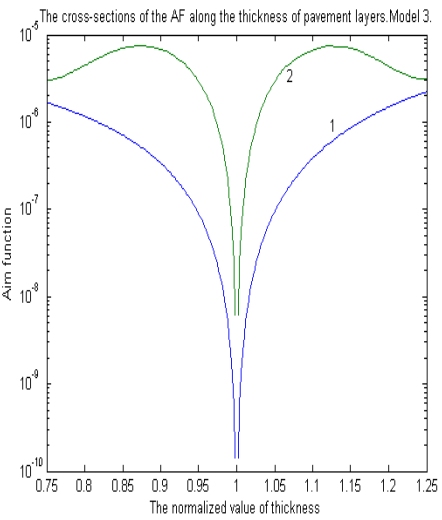

Figure 4. Model-based cross - sections of the AF along the thickness of pavement layers: $\mathrm{a}$ - model 1; $\mathrm{b}-$ model 2; $\mathrm{c}-$ model 3 (digit near the line is the number of layer)

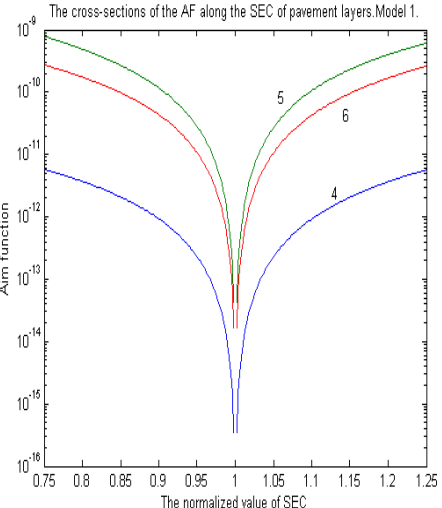

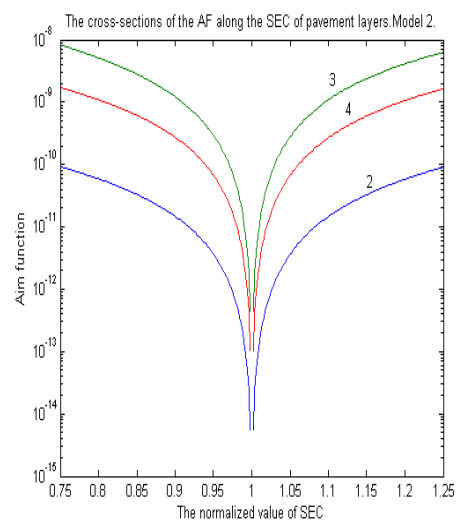

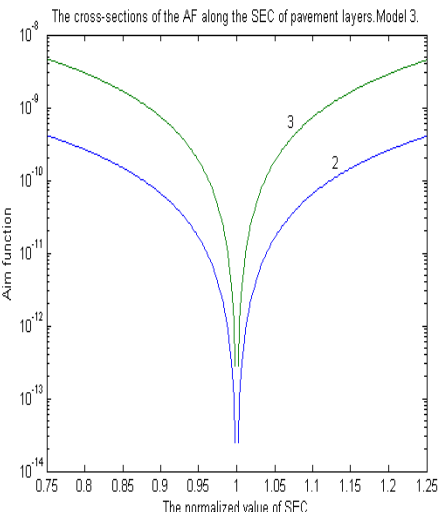

c

Figure 5. Model-based cross - sections of the AF along the specific electrical conductivity of pavement layers: a - model 1; $\mathrm{b}-$ model 2; $\mathrm{c}-$ model 3 (digit near the line is the number of layer)

Unequal sensitivity of aim function (1) explains the relative errors of reconstruction of the electro-physical characteristics of models of roadway construction and their dependence on the search interval width (Table 4 and Table 6). The higher the sensitivity of aim function $\Phi$ to the changing in the electro-physical characteristic of models of roadway construction, the smaller the relative errors of reconstruction of the electro-physical characteristics of models of roadway construction.

The results of reconstruction of similar electro-physical characteristics of layers of roadway constructions for all models coincide, that is why the further research of reconstruction of electro-physical characteristics operates with model 1 of the roadway construction.

Figure 6 demonstrates the dependencies of mean value of obtained minimal values of aim function (the error of finding the global minimum of aim function) from the number of iterations at six values of $f_{\max }\left(\mathrm{F}_{\mathrm{m}}\right)$. In case of decreasing $f_{\max }$ the obtained minimum value of aim function diminishes by an order of magnitude. The errors of reconstruction of electro-physical characteristics of layers have bigger values at lower values of $f_{\max }$. Table 6 presents the relative errors of electro-physical characteristics 
reconstruction of model 1 of roadway construction at different $f_{\max }$ after accomplishing the $100^{\text {th }}$ iteration of BA. The width of relative parameters searching interval equals $50 \%$.

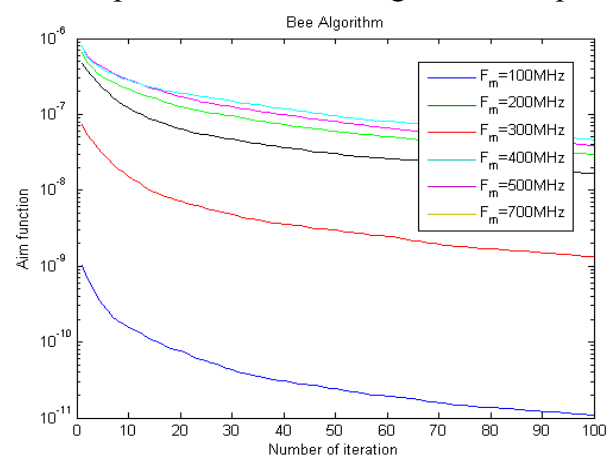

Figure 6. Influence of $f_{\max }$ on convergence of BA (model 1 of roadway construction)

Table 6 presents the relative errors of electro-physical characteristics reconstruction of model 1 of roadway construction at different $f_{\max }$ after accomplishing the $100^{\text {th }}$ iteration of BA. It is seen that the relative errors of reconstructing the thickness of three upper layers are less than 5\% and relative errors of reconstructing the relative dielectric permittivity of two upper layers are less than $3 \%$ at $f_{\max } \geq 500 \mathrm{MHz}$. The expansion of frequency range does not affect the accuracy of reconstruction of the thickness of two lower layers. This is supported by Figure 7 and Figure 8, which show the cross-section of the aim function along the thickness of all layers (Figure 7) and along the relative dielectric permittivity of the upper three layers (Figure 8) of model 1 roadway construction for various $\boldsymbol{f}_{\boldsymbol{m a x}}$.

Table 6. Influence of $f_{\max }$ on the relative errors of reconstruction of the electro-physical characteristics of models 1 roadway construction

\begin{tabular}{|c|c|c|c|c|c|c|}
\hline \multirow{2}{*}{ Electro-physical characteristics } & \multicolumn{6}{|c|}{$f_{\max }, \mathrm{MHz}$} \\
\hline & 100 & 200 & 300 & 400 & 500 & 700 \\
\hline $\mathrm{h}_{1}$ & 8.8 & 10.5 & 13.7 & 6.2 & 4.2 & 4.6 \\
\hline $\mathrm{h}_{2}$ & 15.5 & 17.3 & 5.7 & 3.7 & 2.7 & 3.2 \\
\hline$h_{3}$ & 14.4 & 12.2 & 9.7 & 8.2 & 4.9 & 3.7 \\
\hline $\mathrm{h}_{4}$ & 12.3 & 6.7 & 6.3 & 6.1 & 8.0 & 8. \\
\hline $\mathrm{h}_{5}$ & 6.6 & 4.5 & 5.0 & 7.1 & 5.7 & 7.4 \\
\hline$\varepsilon_{1}^{\prime}$ & 0.7 & 0.7 & 0.5 & 0.5 & 0.4 & 0.3 \\
\hline$\overline{\varepsilon_{2}^{\prime}}$ & 5.9 & 6.4 & 2.5 & 2.8 & 2.4 & 2.7 \\
\hline$\varepsilon_{3}^{\prime}$ & 12.3 & 7.8 & 10.4 & 10.8 & 9.2 & 8.4 \\
\hline$\varepsilon_{4}^{\prime}$ & 13.2 & 11.3 & 12.8 & 11.0 & 12.1 & 12.3 \\
\hline$\varepsilon_{5}^{\prime}$ & 14.4 & 13.0 & 13.3 & 14.3 & 13.4 & 13.5 \\
\hline$\varepsilon_{6}^{\prime}$ & 14.3300 & 15.4100 & 14.8700 & 13.7900 & 14.9 & 13.3400 \\
\hline$\sigma_{4}$ & 15.7 & 16.3 & 15.5 & 15.3 & 13.5 & 15.4 \\
\hline$\sigma_{5}$ & 15.1 & 14.4 & 15.2 & 15.3 & 15.1 & 14.8 \\
\hline$\sigma_{6}$ & 15.6 & 15.3 & 13.7 & 14.8 & 14.8 & 16.0 \\
\hline
\end{tabular}




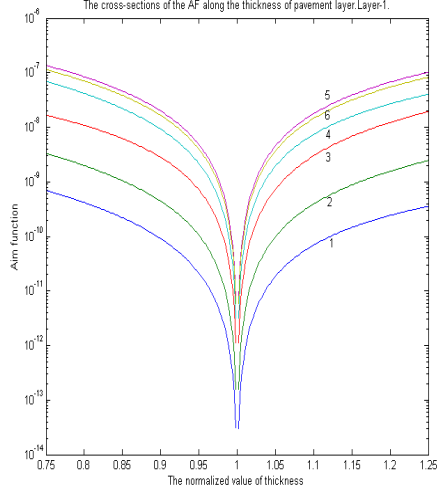

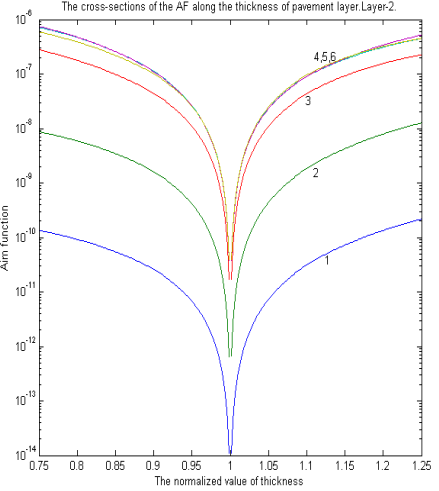

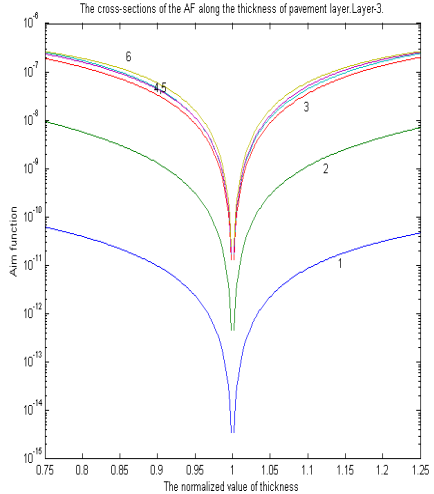

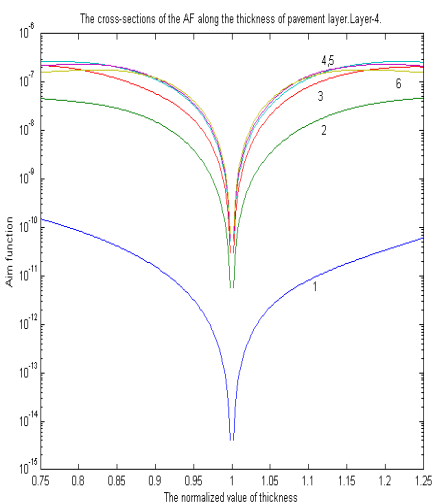

$\mathrm{d}$

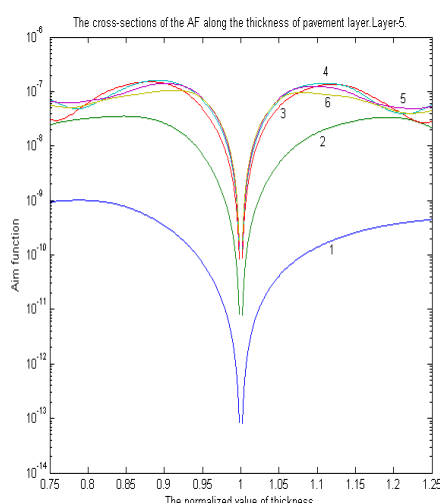

Figure 7. Model-based cross - sections of the aim function along the thickness of pavement layers: a - 1-st layer; b - 2-nd layer; c-3-rd layer; d - 4-th layer; e - 5-th layer; f-6-th layer (digit near the line: $1-f_{\max }=100 \mathrm{MHz}, 2-f_{\max }=200 \mathrm{MHz}$, $\left.3-f_{\max }=300 \mathrm{MHz}, 4-f_{\max }=400 \mathrm{MHz}, 5-f_{\max }=500 \mathrm{MHz}, 6-f_{\max }=700 \mathrm{MHz}\right)$

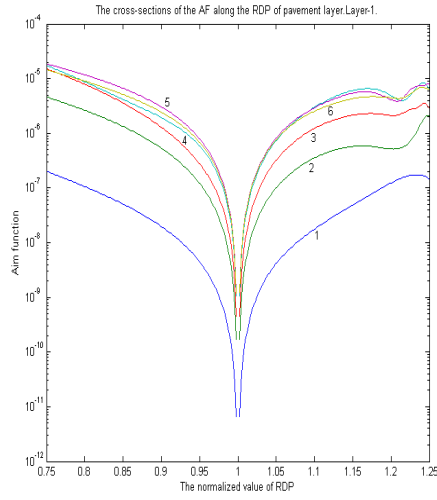

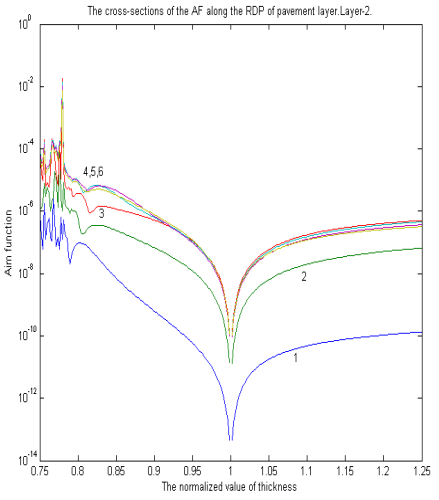

b

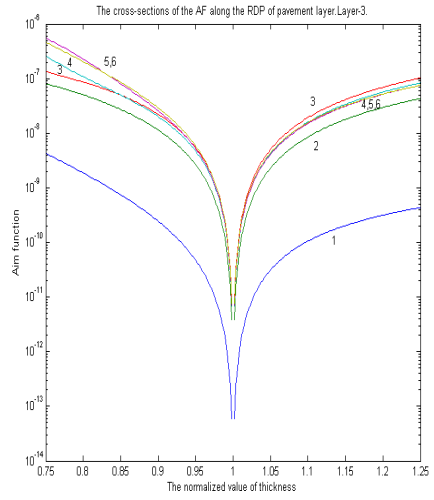

Figure 8. Model-based cross - sections of the aim function along the relative dielectric permittivity of pavement layers: $\mathrm{a}-1$-st layer; $\mathrm{b}-2$-nd layer; $\mathrm{c}-3$-rd layer; (digit near the line: $1-f_{\max }=100 \mathrm{MHz}, 2-f_{\max }=200 \mathrm{MHz}, 3-f_{\max }=300 \mathrm{MHz}$, $4-f_{\max }=400 \mathrm{MHz}, 5-f_{\max }=500 \mathrm{MHz}, 6-f_{\max }=700 \mathrm{MHz}$ )

The aim function $\Phi(1)$ increases along each electro-physical characteristics, if the value of $f_{\max }$ increases. But when the $f_{\max }$ exceeds $400 \mathrm{MHz}$, aim function $\Phi$ increases insignificantly, and the sensitivity of aim function $\Phi$ to the changing in the electro-physical characteristic of model of roadway construction. Therefore, the value $f_{\max }=500 \mathrm{MHz}$ has been used in the process of employment of BA and $\mathrm{ABC}$ algorithms for solving the inverse problem, since the relative errors of reconstruction of characteristics do not diminish significantly at big values of $f_{\max }$, but the number of operations in the process of calculating the AF increases, and accordingly the time of inverse problem solving also increases. 
The research has investigated the impact of local searching of BA for an error of finding the minimum of aim function and for relative errors of reconstruction of the electro-physical parameters of model 1 of roadway construction. The relative searching interval at each electro-physical parameter equals $50 \%$. The number of the fittest selected sites and number of elite sites employed for implementation of local searching for global minimum of aim function does not affect the results of solving the inverse problem. In the percentage term the size of the site for local searching must be not less than $3 \%-5 \%$ from the searching interval width according to the corresponding coordinate. Otherwise the efficiency of local searching decreases: the errors of determining the minimal value of aim function increase and the relative errors of reconstruction of electro-physical parameters of roadway layers grow.

Maximum number of last iterations, not followed by improvement of the aim function value employs for algorithm operating accomplishment. The error of finding the global minimum of the aim function and dispersion of values decreases while this parameter is growing (Fig. 9a). Nevertheless, the total number of iterations till the algorithm operating accomplishment grows, consequently the time of the inverse problem solving increases. (Fig.9b) The number of iterations till the algorithm BA operating accomplishment has almost linear dependence with number of iterations, not followed by improvement. The relative root mean square deviation of number of iterations till the algorithm operating accomplishment decreases in case of increasing number of iterations without improvement.

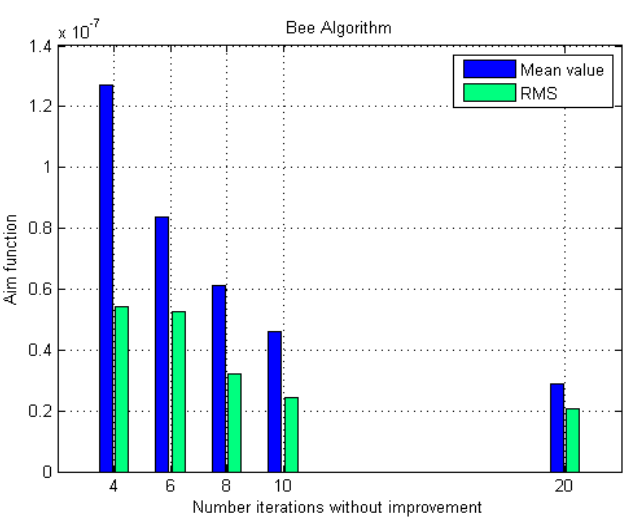

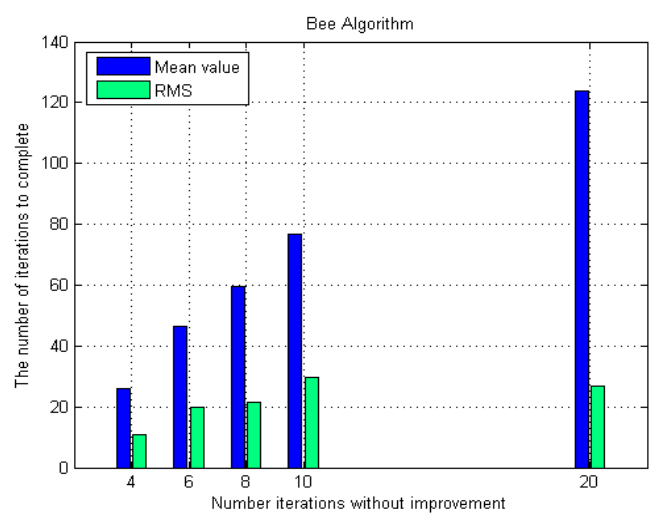

Figure 9. Influence of maximum number of last iterations without improvement of the aim function value on the error minimization of aim function (a) and the total number of iterations BA (b)

Increasing the number of iterations, not followed by improvement of the aim function value also increases the probability of localisation of reconstructed values of thickness. Nevertheless, the relative error of reconstruction decreases only for thickness of the first three layers under the values close to $5 \%$. The errors of reconstruction of thickness of the fourth and the fifth layers also decrease in case of growing number of iterations without the aim function improvement; however the error value is more than $5 \%$ (Fig. 10a and 10b).

The probability of localisation of the modelled value of relative dielectric permittivity of the first layer equals to 1 at any number of iterations without the aim function improvement, and the error of reconstruction of electro-physical characteristic is less than 1\% (Fig. 10c and 10d). An increase of the number of iterations without the aim function improvement does not decrease the relative error of reconstruction of relative dielectric permittivity of other layers. The probability of localisation of the reconstructed value of relative dielectric permittivity of other layers is several times less than 1 even in case the probability of localisation grows under the condition of increasing the number of iterations without the aim function improvement. The number of iterations without the aim function improvement does not affect the localisation probability and relative errors of reconstruction of relative dielectric permittivity of the layers (Fig. 10e and 10f).

The analysis of impact of number of iterations without the aim function improvement on the results of solving the inverse problem allows concluding that the value of this characteristic must be in the interval 6...12. An increase of the number of bees-scouts of BA has insignificant impact on probability of localisation of the reconstructed values of thickness of the first and the second layers, providing the value of the relative error of reconstruction of thickness of the first two layers less than 5\%. The errors of reconstruction of thickness of the lower three layers do not depend on the number of bees-scouts; 
the values of errors are more than $5 \%$. The probability of localisation of the modelled value of the relative dielectric permittivity of the first layer equals to 1 at any number of bees-scouts; the error of reconstruction of this electro-physical parameter is less than $1 \%$
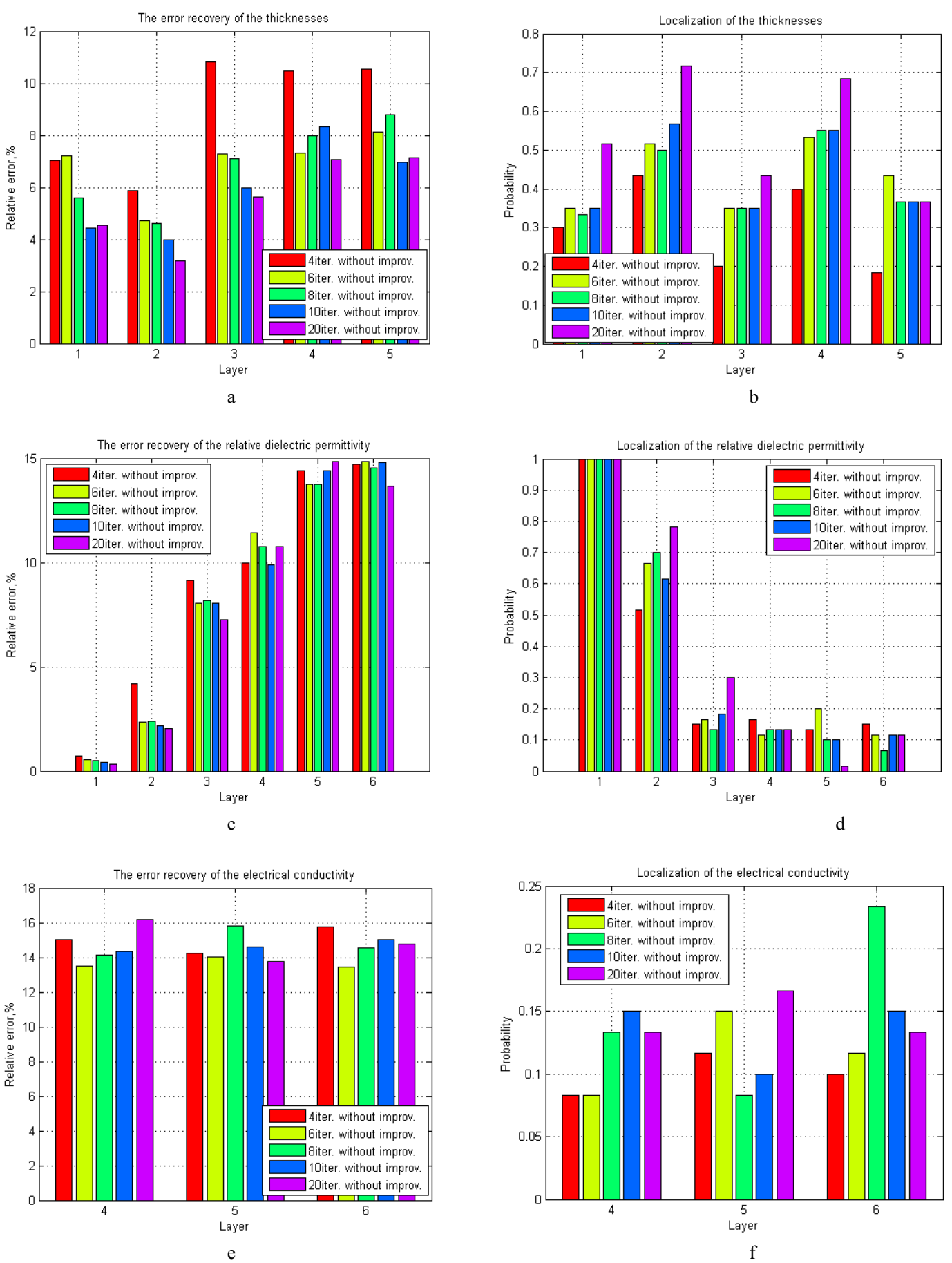

Figure 10. Influence of maximum number of last iterations without improvement of the aim function value on reconstruction by BA the electro-physical parameters of model 1 of roadway

When $\mathrm{ABC}$ algorithm is used the impact of the number of bees-scouts on the error of finding the global minimum of the aim function is insignificant. Figure 11 presents the influence of maximum number of iterations without improvement on the solution of the inverse problem with employment ABC algorithm. Increasing the value of this free argument till 20 can decrease the mean value of the obtained minimal values of the aim function by an order of magnitude. 


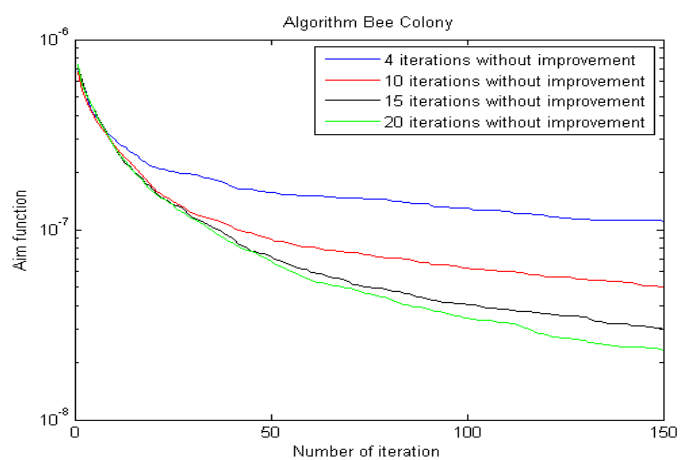

Figure 11. Influence of maximum number of last iterations without improvement of the aim function value on convergence of $\mathrm{ABC}$ algorithms (model 1 of roadway construction)

Nevertheless, the impact of this parameter on reconstruction of electro-physical characteristics of layers of model 1 of the roadway construction is different (Fig. 12).

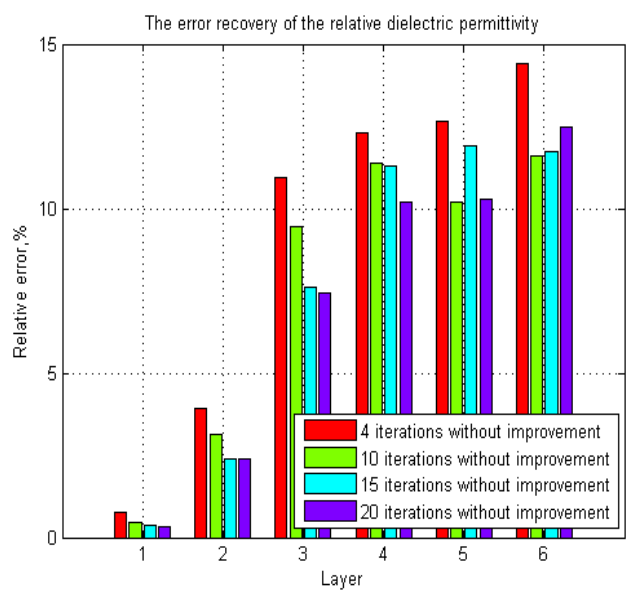

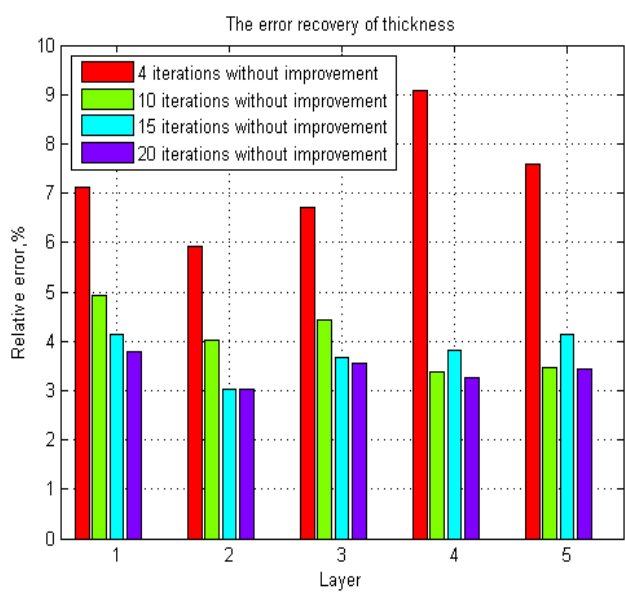

b

Figure 12. Influence of maximum number of last iterations without improvement of the aim function value on relative errors of reconstruction relative dielectric permittivity and the thickness of roadway construction layers by $\mathrm{ABC}$ algorithms (model 1 of roadway construction)

As it has been mentioned above, the errors of reconstruction of relative dielectric permittivity of two upper layers have low values, and increasing the number of iterations without improvement makes them even lower (Fig. 12a). The parameter of ABC algorithm under consideration has no influence on the relative error of reconstruction of relative dielectric permittivity of other layers. Figure $12 \mathrm{~b}$ demonstrates the impact of number of iterations without improvement on relative errors of reconstruction of thickness of all layers of modelled roadway construction. Increasing the number of iterations without improvement decreases the relative errors of reconstruction of thickness of all layers to the values, which are lower than $4 \%$. The number of iterations without improvement has no impact on relative error of reconstruction of relative dielectric permittivity of all layers.

\section{Conclusions}

The main results of employment of $\mathrm{BA}$ and $\mathrm{ABC}$ algorithms are as follows:

- the error of minimisation of the aim function mainly depends on the width of the searching interval of electro-physical characteristics;

- the value of the relative error of reconstruction of electro-physical characteristics depends on the ordinal number of the layer, the type of electro-physical characteristic, and width of the searching interval;

- the maximum number of spectral components must be used for the aim function calculations for decreasing the error of reconstruction of electro-physical characteristics; 
- when BA algorithm is used the maximum number of iterations, not followed by improvement of the aim function and size of neighbourhood of local searching are the only factors allowing decreasing the error of reconstruction of thickness and relative dielectric permittivity of layers of roadway construction and permitting growth of probability of localisation of reconstructed value in the specified interval;

- when BA algorithm is used the maximum number of iterations, not followed by improvement of the aim function must be selected from the interval 6-12, the relative size of sites for local searching must be not less than $3 \%-5 \%$ and the number of bees-scouts must be no fewer than 20 for minimising the number of algorithm iterations;

- when BA algorithm is used It has been determined that the number of bees-scouts has no impact on the aim function minimisation and on error of reconstruction of electro-physical characteristics, but the maximum number of iterations, not followed by improvement of the aim function values must be selected from the interval 10-20;

- these values of this parameter of $\mathrm{ABC}$ algorithm allow reconstructing the thickness of layers with error less than $5 \%$ at any a priori information; this function is not provided by Genetic algorithm and BA.

\section{References}

1. Saarenketo, Timo. Monitoring Low Volume Roads. Executive Summary. August 2006, from http://www.roadex.org/uploads/publications/docs-RII-S-EN/Monitoring_English.pdf

2. COST 325.Pavement Condition Monitoring, from http://www.fehrl.org/index.php?id=300\&m=155\&mode=more

3. Attoh-Okine, Nii O., Mensah, Stephen. MEMS Application in Pavement Condition Monitoring Challenges, from http://fire.nist.gov/bfrlpubs/build02/PDF/b02052.pdf

4. Saarenketo, Timo. Load Restriction Policies, Monitoring and rehabilitation. April 2005, from http://www.roadex.org/uploads/publications/docs-RII-EN/2_3\%20Spring_Thaw_Weakening_1.pdf

5. Ground penetrating radar: theory and applications / Editor Harry M. Jol. Elsevier Science, 2009. $524 \mathrm{p}$.

6. Problems of subsurface radiolocation. Collective monograph / Ed. by A. Yu. Grinev. M.: Radiotehnika, 2005. 416 p. (In Russian)

7. Krainyukov, A., Kutev, V., Opolchenov, D. (2010). Reconstruction of the Roadway Inner Structure Electro-physical Characteristics. In Proceedings of the $10^{\text {th }}$ International Conference "Reliability and Statistics in Transportation and Communication” (RelStat'10), 20-23 October 2010 (p. 55). Riga, Latvia: Transport and Telecommunication Institute.

8. Pham, D. T., Ghanbarzadeh, A., Koc, E, Otri, S, Rahim, S., Zaidi, M. (2005). The Bees Algorithm. Technical Note. Cardiff, UK: Manufacturing Engineering Centre, Cardiff University.

9. Karaboga, D. (2005). An idea based on honey bee swarm for numerical optimization. Erciyes University, Engineering Faculty, Computer Engineering Department. Technical report - TR06.

10. Krainyukov, A., Kutev, V., Andreeva, E. (2013). Solving of Radar Pavement Monitoring Inverse Problem by Using of Bees Algorithms. In Proceedings of the $13^{\text {th }}$ International Conference "Reliability and Statistics in Transportation and Communication" (RelStat'13), 16-19 October 2013 (p. 277). Riga, Latvia: Transport and Telecommunication Institute.

11. Ceļu specifikācijas 2012 ar AS “Latvijas Valsts ceļi” Tehniskajā komisijā 2013. gada 29. maijā apstiprinātajiem grozījumiem, from http://lvceli.lv/lat/sadarbibas_partneriem/normativie_dokumenti/autocelu_specifikacijas

12. Krainyukov, A., Kutev, V. (2011). Problem of Road Coverage Quality Estimation by GPR Probing Method. Transport and Telecommunication, 12(4), 4-12. 